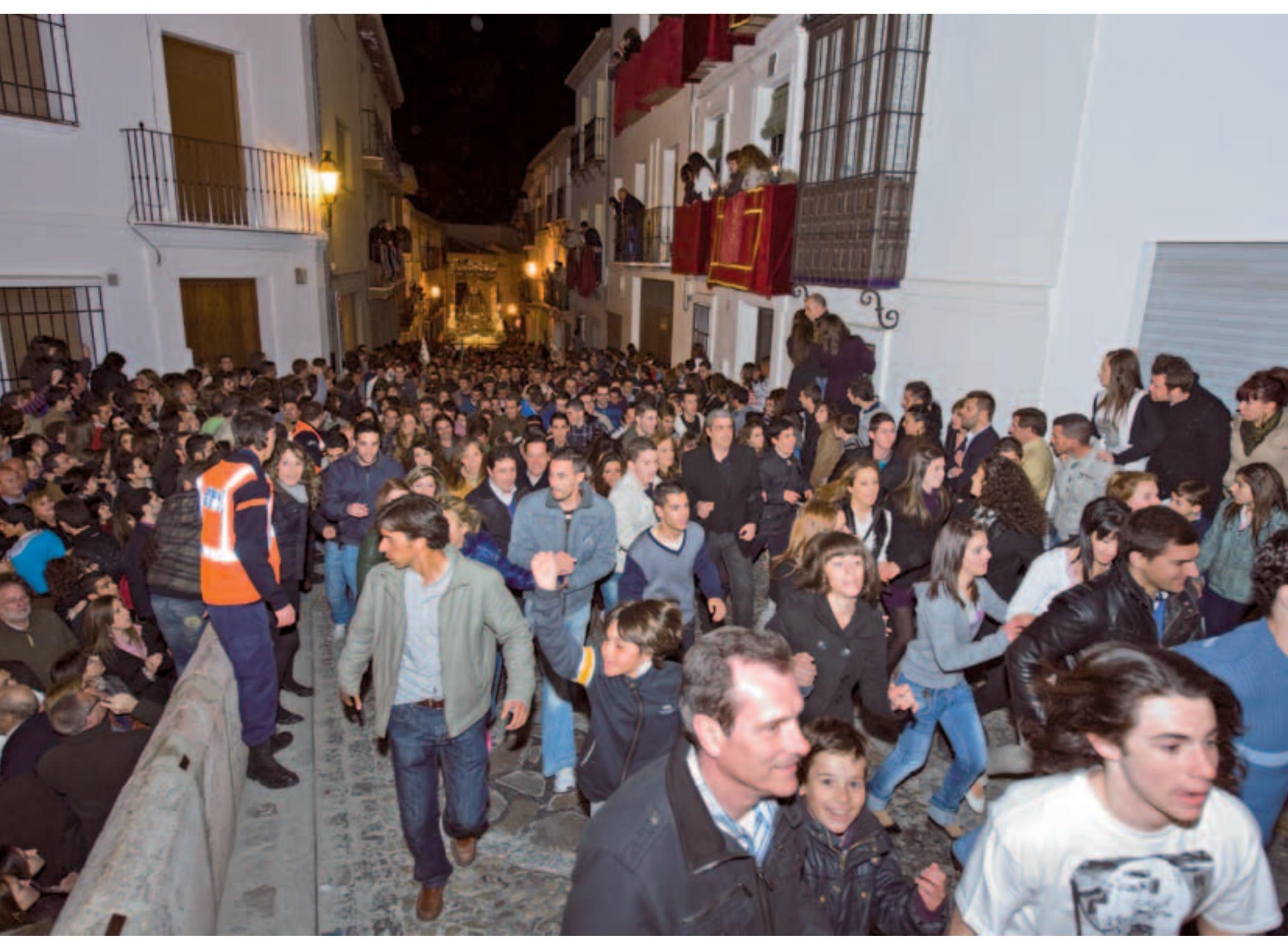

El trono de la Virgen del Socorro (hermandad de Arriba) y la multitud que lo precede corren su vega. Foto: Juan Carlos Cazalla, IAPH 


\section{Correr la vega. Dicotomías sociales y ritual en la Semana Santa de Antequera}

Isidoro Moreno Navarro, Grupo de Investigación GEISA, Dpto. de Antropología Social, U. de Sevilla

En numerosas ciudades y pueblos andaluces, la Semana Santa, más allá de su explícita dimensión religiosa, constituye un "hecho social total", tal como definió esta categoría, hace ya casi un siglo, el antropólogo francés Marcel Mauss (MORENO NAVARRO, 2008). Entonces, reflejando directamente la estructura social local de la sociedad que la celebra o, a veces, invirtiendo o incluso negando ésta en algunas o muchas de sus facetas (MORENO NAVARRO, 1999; 2006a), todas las dimensiones de la vida social -simbólica, identitaria, política, económica...- intervienen o se ven afectadas por la Semana Santa y todos, o la gran mayoría, de los grupos sociales participan, de una manera u otra, en este fenómeno sociocultural o, al menos, se definen o sitúan explícitamente respecto a él. Casi nada y casi nadie permanece ajeno o indiferente al mismo.

Es ésta una de las razones principales de que en Andalucia, contrariamente a lo que ocurre en la mayor parte de las regiones mediterráneas, incluido el Estado Español, la Semana Santa continúe siendo, en la época de la glocalización (MORENO NAVARRO, 2010), uno de los referentes de la identidad cultural (MORENO NAVARRO, 2000a; 2000b). Pocos lugares como Antequera donde esta afirmación esté más respaldada. La historia antequerana, desde casi el momento mismo de la conquista castellana hasta hoy, se ha reflejado en su Semana Santa. Y puede ser entendida a través del análisis de ésta, tanto en sus continuidades como en sus cambios (MORENO NAVARRO; TÁVORA, 1989).

La sociedad antequerana, tras la conquista y recristianización, se construyó sobre un doble dualismo. Por una parte, familias nobles grandes propietarias de feraces tierras, que constituian la base de su poder económico y social, monopolizando los cargos claves del poder municipal, y un alto número de trabajadores, sin tierras o con muy pocas y sin ningún poder, al servicio de estos. Sólo en un periodo, ya del siglo XIX, en que proliferaron las industrias textiles, se complejizó dicha dicotomía o fractura social, que sigue reflejándose en el urbanismo de la ciudad y en sus edificios. Pocas agrociudades como Antequera con más alta concentración de iglesias, conventos y palacios que contrastan con las modestas y blanquísimas casas del común de los vecinos.
Esta dicotomía de clases se tradujo, en los rituales y protagonismos de la Semana Santa, en elementos e incluso términos muy significativos y singularmente antequeranos. Por una parte, los hermanos mayores de insignia, con túnicas de terciopelo ricamente bordadas y la cara descubierta, con todo el poder sobre los tronos en los que desfilan las imágenes emblemáticas, y los campanilleros de lujo -niños con túnicas de larga cola bordada, que arrastra, y joyas en su cabeza-. Unos y otros pertenecientes a las más importantes familias. Por otra, los hermanacos, portadores de los pesados tronos llevando las horquillas con que se ayudan para descansar en las paradas y utilizan como palanca para tomar impulso en el trabajoso discurrir por las cuestas urbanas. A aquellos les corresponde el mando; a estos la obediencia. Se repite en cada cofradía y se visibiliza en sus procesiones la estructura de poder y subalternidad que regía la sociedad local en todos los ámbitos hasta la quiebra de las bases económicas de dicha estructura, en los años sesenta del siglo XX.

Pero no ha sido este dualismo -propietarios aristócratas versus campesinos sin tierra o con escasa propiedad-, traducido en hermanos mayores versus hermanacos en los rituales semanasanteros, el único presente en el devenir histórico de los casi seiscientos últimos años de una población varias veces milenaria. También, hasta entrado el siglo XX, persistió otra dicotomía: la existente entre dos conjuntos de familias poderosas enfrentadas permanentemente, que proyectaban su rivalidad en todas las facetas de la vida social incluyendo, de forma muy principal, el ámbito religioso y ritual, arrastrando tras ellos a sus respectivas clientelas y sectores dependientes. Encabezados por Chacones y Narváez, que fueron los dos linajes principales de la ciudad desde su toma por el Infante don Fernando en 1410, todos cuantos poseían parcelas de poder se agruparon en uno y otro bando, que impulsó y protegió a concretas órdenes religiosas, a su vez en rivalidad-especialmente dominicos y franciscanos-, y a las cofradias patrocinadas por éstas, las de "Arriba" y "Abajo", enfrentadas desde su misma fundación a finales del siglo XVI.

Estas dos dicotomías fueron los dos ejes, imbricados, a partir de los cuales se desarrolló la sociedad local y se constituyó su Sema- 


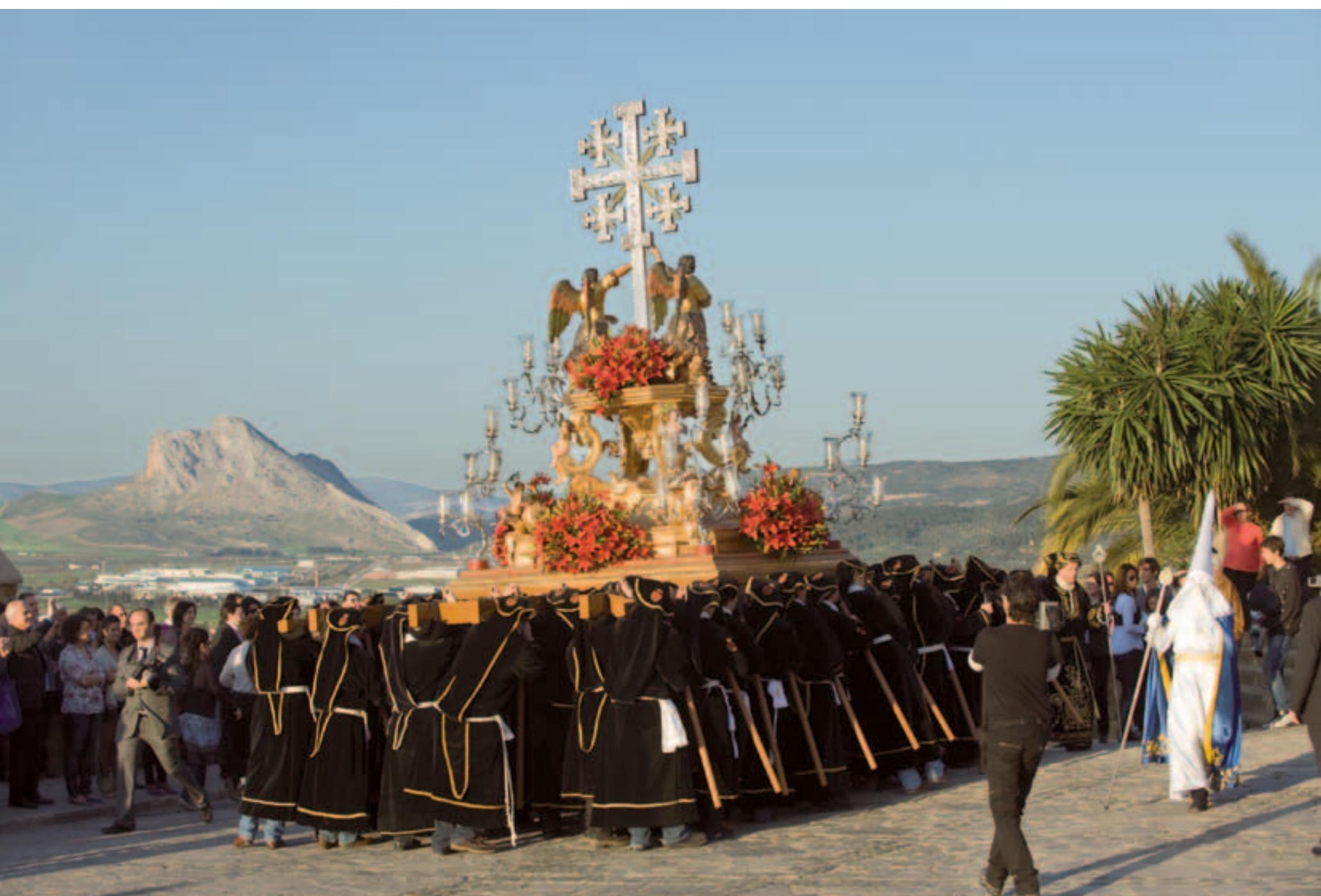

Trono de la Santa Cruz en Jerusalén, de la hermandad de Arriba, a poco de salir, sobre los campos y con la Peña de los Enamorados al fondo. Foto: Juan Carlos Cazalla, IAPH

con dieciséis varales o barras y otro, el de la Paz, que lleva doce agrupados en las cuatro esquinas. Y se ha recuperado el palio para un trono de Cristo, el del Nazareno de la Sangre de la hermandad de los Estudiantes...

También destacan, como momentos de alta emocionalidad, los Encuentros de los tronos de las dos cofradías del jueves y de la de Arriba y la de Abajo, el viernes. En el primer caso, se trata de la cofradía del Consuelo, de la parroquia de San Pedro, con la Virgen de este nombre -que va en el trono que pasa por ser el que más responde al "modelo sevillano"- y el Cristo de la Misericordia, y de la cofradia Servita del convento de Belén, con el Cristo amarrado a la columna, el Nazareno del Consuelo y la Virgen de los Dolores. Y el viernes se encuentran los cuatro tronos de la hermandad de Abajo con los tres de la de Arriba, en la plaza de San Sebastián.

Son estas cuatro hermandades las que "corren vegas". Correr la vega es, sin duda alguna, el elemento que más identifica y singulariza a la Semana Santa de Antequera. Quienes están presentes por primera vez pueden tener la sensación de asistir a una especie de sanfermines a lo divino: Ios tronos, llevados casi en volandas por los hermanacos, ayudándose de sus horquillas que golpean con fuerza el suelo, suben a la carrera empinadas cuestas para llegar al entorno de sus templos mientras una multitud los precede, también corriendo, a la vez abriendo paso y dificultando la subida. Para la carrera, el hermano mayor de insignia se despoja de sus pesados terciopelos, los hermanacos ajustan sus ropas y calzado, los músicos o piquetes militares interpretan marchas ligeras y tratan de despejar el camino. Se ponen en tensión todas las fuerzas. Durante las "vegas" se rompe el dualismo hermano mayor-hermanacos y se establece otra nueva polarización: la de cada trono, con hermanacos y hermanos mayores en gran medida fundidos, y el pueblo anónimo. Y todos corren, delante de la imagen.

Hacen vegas las dos cofradías del jueves, tras su encuentro: el Consuelo en la Cruz Blanca; la de los Dolores en la cuesta de Archidona, en los Cerrillos. Y también, el viernes, tras el suyo, la de Abajo por la cuesta de la Paz y la de Arriba por las cuestas de Zapateros, Viento y Herradores, hasta el Portichuelo. Como suele 


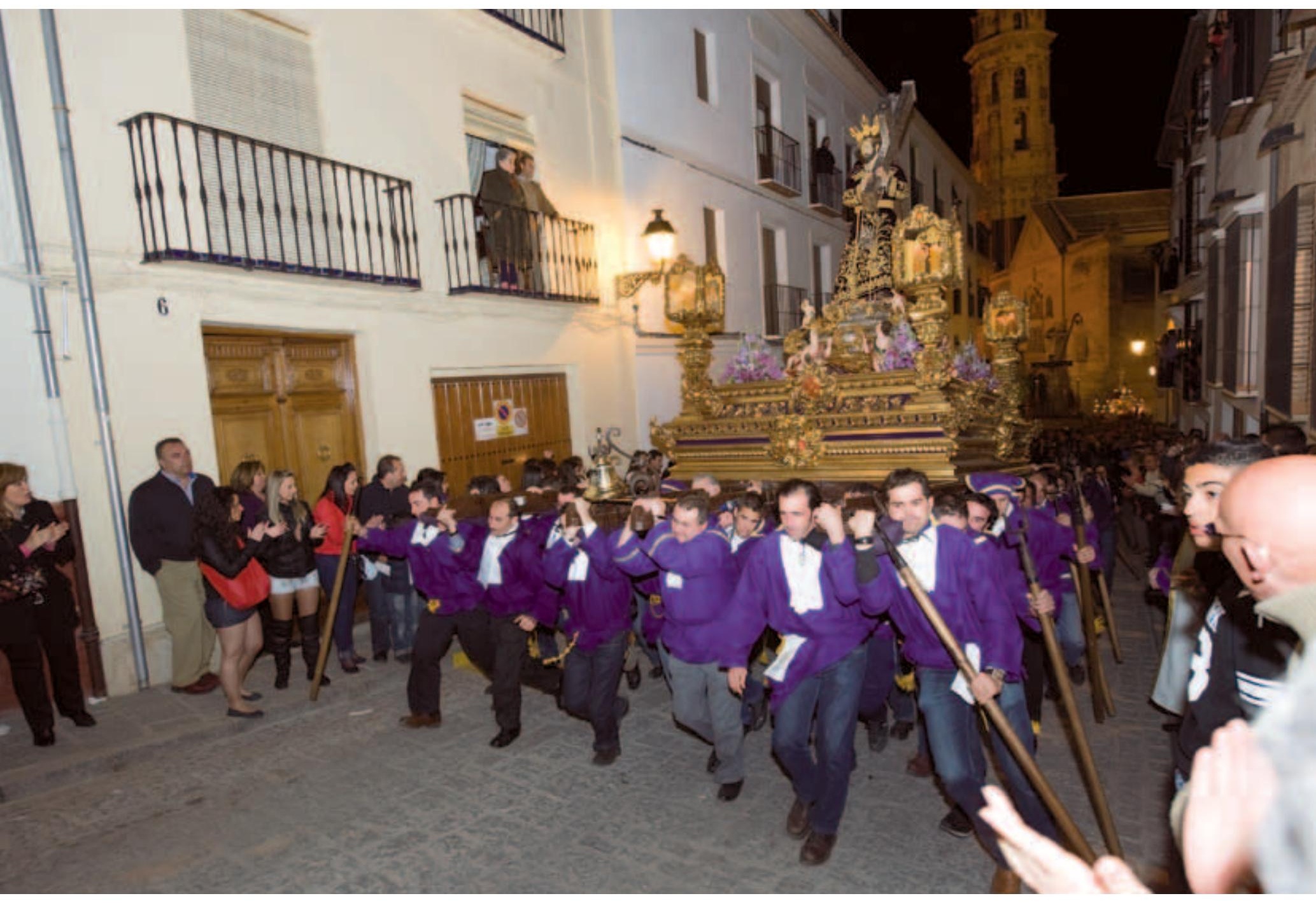

Dulce Nombre de Jesús, de la hermandad de Abajo, corriendo su vega. Foto: Juan Carlos Cazalla, IAPH

suceder, existen varias versiones que tratan de explicar no sólo el hecho sino, sobre todo, su denominación. Una de ellas señala que las imágenes son conducidas a lugares altos de la población para desde ellos bendecir los campos -la vega- para que sigan siendo feraces. Así, el grito de "a la vega" sería una llamada a la bendición sagrada. Y correr la vega sería una especie de rito propiciatorio de fertilidad.

Sin duda, desde la Cruz Blanca se divisan (o, mejor, se divisaban) las huertas. También desde los Cerrillos. Y desde el entorno del Portichuelo -de la capilla-tribuna de la Virgen del Socorro- pueden verse los campos, desde la Peña de los Enamorados hasta casi las cercanías de El Torcal. Pero también existe la versión historicista. Según las crónicas que alimentan la leyenda, el día de la conquista, 16 de septiembre, los cristianos persiguieron a los moros hasta lo alto de la fortaleza llevando con ellos una imagen de la Virgen y los allí sitiados tuvieron que escapar por la vega entregando la ciudad. Así, el grito de guerra para obligarles a huir, para echarlos "a la vega", haciéndoles abandonar el castillo y escapar por los campos, se habría convertido en el
Durante las "vegas" se rompe el dualismo hermano mayor-hermanacos y se establece otra nueva polarización: la de cada trono, con hermanacos y hermanos mayores en gran medida fundidos, y el pueblo anónimo. $Y$ todos corren, delante de la imagen 


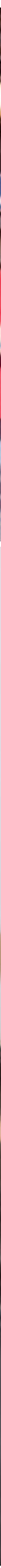

1. Encuentro entre las Vírgenes de los Dolores y del Consuelo, la noche del Jueves Santo.

2. Trono del Cristo de la Misericordia (hermandad del Consuelo) corriendo la vega.

3. La Virgen de la Paz (hermandad de Abajo) corre la vega.

Fotos: Juan Carlos Cazalla, IAPH

grito de ánimo a los hermanacos para que sea posible culminar
Si una u otra versión se ajusta más a la realidad histórica, o si ambas tienen su parte de verdad y su parte de mito, es poco im- portante. Porque lo que explica principalmente el que se sigan corriendo las vegas es que constituyen los momentos de clímax de los rituales semanasanteros antequeranos hasta el punto de haberse convertido en uno de los referentes identitarios de la sociedad local. Por encima de los diversos dualismos, pasados y actuales, e integrándolos. 